\begin{tabular}{|c|l|}
\hline Title & Boiling behaviors and critical heat flux on a horizontal plate in saturated pool boiling of water at high pressures \\
\hline Author(s) & Sakashita, Hiroto; Ono, Ayako \\
\hline Citation & $\begin{array}{l}\text { International Journal of Heat and Mass Transfer, 52(3-4), 744.750 } \\
\text { https://doi.org/40.1016/.ijheatmasstransfer.2008.06.040 }\end{array}$ \\
\hline Issue Date & 2009-01-31 \\
\hline Doc URL & http://hdl.handle.net/2115/42770 \\
\hline Type & article (author version) \\
\hline File Information & IJHMT52-3-4_744.750.pdf \\
\hline
\end{tabular}

Instructions for use 
(The revised final manuscript (Y/M07065))

\section{Boiling Behaviors and Critical Heat Flux on a Horizontal Plate in Saturated Pool Boiling of Water at High Pressures}

$$
\text { Hiroto SAKASHITA }{ }^{a, *} \text { and Ayako ONO a }
$$

a Division of Energy and Environmental Systems, Graduate School of Engineering, Hokkaido University, North 13 West 8, Kita-ku, Sapporo 060-8628, Japan

* Corresponding author. Tel.: +81 11706 6664, Fax.: +81 117066664 E-mail address: saka@eng.hokudai.ac.jp 


\begin{abstract}
Observations of boiling behaviors and measurements of critical heat flux $(\mathrm{CHF})$ were carried out for saturated water boiling on a horizontal, upward-facing plate at pressures from atmospheric to $7 \mathrm{MPa}$. The primary bubbles diminish in size almost in inverse proportion to pressure and commence to coalesce in the very low heat flux region. The diameter of detached coalesced bubbles increases with increases in the heat flux and reaches about $10 \mathrm{~mm}$ even at a pressure of $5 \mathrm{MPa}$. Detachment frequency of the coalesced bubbles was unaffected by the heat flux and pressure. The CHF predicted based on the macrolayer dryout model agrees well with the measured data.
\end{abstract}

Key words : Pool boiling, Critical heat flux, High pressure, Macrolayer, Observation, Primary bubble, Coalesced bubble 


\section{Nomenclature}

$A \quad$ constant in equation (12)

$C_{D} \quad$ drag coefficient

$C_{O} \quad$ constant in drag coefficient

$D_{d} \quad$ bubble diameter at detachment

$f \quad$ detachment frequency of bubbles

$G_{0} \quad$ vapor blowing rate, $q /\left(\rho_{v} \cdot H_{f g}\right)$

$g \quad$ gravitational acceleration

$H_{f g} \quad$ latent heat of evaporation

$K \quad$ constant in equation (6)

$M \quad$ Morton number, $g\left(\rho_{l}-\rho_{v}\right) \rho_{l}{ }^{2} v_{l}^{4} / \sigma^{3}$

$m \quad$ exponent in drag coefficient

$N_{E o} \quad$ Eötvös number, defined by equation (3)

$N_{J a}{ }^{*}$ modified Jakob number, defined by equation (4)

$p \quad$ pressure

$q \quad$ heat flux

$q_{C H F}$ critical heat flux

$R_{d} \quad$ bubble radius at detachment

$r \quad$ bubble radius

Re bubble Reynolds number, defined by equation (11)

$s \quad$ distance between center of bubble and heating surface

$T_{\text {sat }} \quad$ saturation temperature

Greek symbols

$\delta_{1} \quad$ macrolayer thickness

$\lambda \quad$ Taylor instability wave length, defined by equation (5)

$\sigma \quad$ surface tension 
$\rho \quad$ density

$\nu \quad$ kinematic viscosity

Subscripts

$1 \quad$ liquid

V vapor 


\section{Introduction}

Theoretical models of the critical heat flux (CHF) in saturated pool boiling have been developed mainly based on experimental results obtained near atmospheric pressure. Based on the various experimental results obtained at atmospheric pressure, Katto and Yokoya [1] proposed the liquid macrolayer dryout model in which $\mathrm{CHF}$ occurs when a macrolayer formed beneath large coalesced bubble dries out just before the departure of the coalesced bubble. This model is formulated as

$$
q_{C H F}=\rho_{l} H_{f g} \delta_{l} \cdot f,
$$

where $\delta_{l}$ is the average thickness of the liquid resting on a heating surface at the formation of the coalesced bubble.

In saturated nucleate boiling at high heat flux under atmospheric pressure, several investigations confirmed the existence of a liquid-rich layer beneath the large coalesced bubbles by using a conductance probe method $[2,3,4,5]$, an optical probe method [6], or an optical method with transparent heating surfaces $[7,8]$. Ono and Sakashita $[9,10]$ measured liquid-vapor behaviors in the vicinity of a heating surface by using a conductance probe method for saturated and subcooled pool boiling in the subcooling range from $0 \mathrm{~K}$ to $40 \mathrm{~K}$ where large coalesced bubbles are able to form and detach from the heating surface. Through these measurements, they confirmed that there is a macrolayer beneath the coalesced bubbles even at very high heat fluxes in subcooled boiling above the CHF in saturated boiling, and the dryout of the macrolayer occurs locally at a high heat flux region close to the $\mathrm{CHF}$ and spreads rapidly over the surface with slight increases in the heat flux. In transition boiling under atmospheric pressure, the macrolayer evaporates and the heating surface dries out before the coalesced bubble detaches, as indicated by measurements of void fractions near the surface 
with the conductance probe [5,11], measurements of surface temperature fluctuations [12,13], and direct observation of the heating surface [14].

This evidence suggests that the dryout of the liquid macrolayer formed on the heating surface is the trigger of the $\mathrm{CHF}$, and hence the macrolayer dryout model is the appropriate model of the CHF near atmospheric pressure in saturated and subcooled pool boiling accompanied by the formation of large coalesced bubbles. At high pressures, however, it is not established that the macrolayer dryout model would be the appropriate CHF model, because experimental results based on the observations of boiling behaviors at high pressures are too limited to elucidate the CHF mechanism.

One investigation observing boiling behaviors at high pressures was carried out by Semeria [15]. Semeria measured the diameters of primary and coalesced bubbles in water boiling on a horizontal $2 \mathrm{~mm}$ diameter cylinder and made photographic records in the range of heat fluxes from 0.083 to $2.17 \mathrm{MW} / \mathrm{m}^{2}$ at $5 \mathrm{MPa}$ and from 0.023 to $2.23 \mathrm{MW} / \mathrm{m}^{2}$ at $14 \mathrm{MPa}$. According to these experiments, the diameter of primary bubbles decreases almost in inverse proportion to the pressure, and reaches about $10 \mu \mathrm{m}$ at $10 \mathrm{MPa}$. With increasing heat flux, these primary bubbles coalesce and detach as larger coalesced bubbles. Bobrovich et al. [16] also carried out an experiment with water boiling on an upward-facing $2 \mathrm{~mm}$ wide rectangular surface and measured the diameter and frequency of detached bubbles in the range of pressures of 0.1 to $5.35 \mathrm{MPa}$ and heat fluxes of 0.2 to $2.4 \mathrm{MW} / \mathrm{m}^{2}$. Here, Bobrovich et al. showed that the diameter of the detached bubbles increases with the increase in heat flux and the detachment frequencies of the coalesced bubbles do not depend strongly on pressures. Nishikawa et al. [17] observed the boiling behaviors of water on a horizontal $0.3 \mathrm{~mm}$ diameter wire and derived a relation between the diameter and the detachment frequency of 
primary bubbles in the pressure range from 0.005 to $4 \mathrm{MPa}$.

These studies were, however, conducted at low and moderate heat fluxes, and there is no research observing boiling behaviors at high heat flux close to CHF. When the ranges of the heat fluxes of the experiments by Semeria and Bobrobich et al. are non-dimensionalized with the CHF values predicted by Lienhard's correlation [18] (equation (6) shown later), it is estimated that the range of Semeria's experiment is $q / q_{C H F}<0.49$ at $p=5 \mathrm{MPa}$ and $q / q_{C H F}<0.61$ at $p=14 \mathrm{MPa}$, and with Bobrovich et al. $q / q_{C H F}<0.61$ at $p=2.21 \mathrm{MPa}$ and $q / q_{C H F}<0.54$ at $p=5.35 \mathrm{MPa}$, respectively. ${ }^{*}{ }^{1}$ Figure 1 shows the variations in the coalesced bubble diameters measured by Semeria and Bobrivich et al. with heat fluxes and pressures. The value of the heat flux (unit $\mathrm{MW} / \mathrm{m}^{2}$ ) corresponding to each datum is noted beside that of Bobrovich et al. Semeria did not specify the values of heat fluxes on the measurement results of the coalesced bubble diameters, and they were estimated to be about $2 \mathrm{MW} / \mathrm{m}^{2}$ by a comparison with the bubble size in the photographs. As shown in Fig.1, the diameter of coalesced bubbles formed in the heat flux range of the experiments by Semeria and Bobrobich et al. are in the same order as those of primary bubbles detached under atmospheric pressure. As bubble growth becomes slower at higher pressures, bubbles of these sizes may be close to spherical as surface tension influences are stronger than inertia, and therefore, it is doubtful whether such small spherical bubbles can have liquid macrolayers underneath. However, the results by Bobrovich et al. indicate that the diameter of coalesced bubbles tends to increase with the increase in heat flux,

\footnotetext{
${ }^{*}$ When the heat fluxes are non-dimensionalized with a best fit correlation of the present data of the CHF measured up to 7MPa shown later in Fig.10, the heat flux ranges are estimated as $q / q_{C H F}<0.35$ at $p=5 \mathrm{MPa}$ for Semeria's experiment, and $q / q_{C H F}<0.42$ at $p=2.21 \mathrm{MPa}$ and $q / q_{C H F}<0.38$ at $p=5.35 \mathrm{MPa}$ for the Bobrovich et al. experiments.
} 
and it may be possibile that larger coalesced bubbles with the liquid macrolayer underneath are formed at higher heat fluxes near the CHF even at high pressures.

The present study carried out an experiment to observe boiling behaviors of water on an upward-facing horizontal plate at pressures from atmospheric to $5 \mathrm{MPa}$. The diameters and detachment frequencies of bubbles were measured in a wide range of heat fluxes up to the CHF point. Based on the measurements, an empirical correlation of detachment frequencies of coalesced bubbles was derived, and the CHF was predicted with the derived empirical correlation and available correlations of macrolayer thickness derived near atmospheric pressure. By comparing the predicted results with the $\mathrm{CHF}$ data measured in the present study at pressures from atmospheric to $7 \mathrm{MPa}$, the validity of the macrolayer dryout model at high pressures was examined.

\section{Experiments}

Water was used as the boiling liquid. Boiling behaviors were observed in the pressure range from 0.1 to $5 \mathrm{MPa}$, and the $\mathrm{CHF}$ was measured from 0.1 to $7 \mathrm{MPa}$. Figure 2 shows the high-pressure cell used in the present experiment. The cell is cylindrical in shape with an inner diameter of $50 \mathrm{~mm}$, and a height of $150 \mathrm{~mm}$. Sapphire windows and electrodes are installed in both sides of the cell. Figure 3 shows a detail of the test section. The heating surface is made of nichrome, $20 \mu \mathrm{m}$ thick, $4 \mathrm{~mm}$ wide, and $27.5 \mathrm{~mm}$ long and heated with a DC power supply. To avoid end effects on CHF, a clearance of $5 \mathrm{~mm}$ was provided between the supporting plate and the electrodes. As the saturation temperature becomes higher at higher pressures, it is difficult to fix the nichrome foil and the supporting resin plate with adhesives. In the present study, therefore, the 
supporting resin plate was pushed against the heating surface by springs without use of adhesives. To check that there is no inflow of water between the heating surface and the supporting resin plate, an experiment where the heating surface was fixed to the plate with an adhesive was also conducted under atmospheric pressure. As there were no differences between the CHF values measured with the surfaces fixed with the adhesive and with the springs, it was concluded that there was no liquid inflow beneath the heating surface. The heat generated in the electrodes, outside the heating surface was about $5 \%$ of the whole of the heat input, and this was deducted from the heat input in the estimates of the wall heat flux. There was no correction for the heat loss from the heating surface to the supporting resin plate. The wall heat flux was calculated by $Q /(\mathrm{L} \cdot \mathrm{W})$, where $\mathrm{Q}$ is the corrected heat input, $\mathrm{L}$ and $\mathrm{W}$ are length $(27.5 \mathrm{~mm})$ and width $(4 \mathrm{~mm})$ of the metal foil, respectively.

Before each run, the heating surface was polished by emery paper, washed with acetone and distilled water, and then attached to the electrodes. Then the high-pressure cell was filled with de-ionized water (electric conductivity less than $0.2 \mu \mathrm{S} / \mathrm{cm}$ ) and decompressed with a connected vacuum pump to boil the water at room temperature. This decompressed boiling was continued for about half an hour to ensure that the water was fully degassed. Then the water was heated to a saturation temperature by heaters winded around the high- pressure cell and maintained at that level by adjusting the input of the heaters and flow rate of cooling water through cooling coils. In the measurements of $\mathrm{CHF}$, the voltage supplied to the metal foil was increased gradually and the heat flux just when the physical burnout of the foil occurred was defined as the critical heat flux. The boiling behavior was observed using a high-speed video with $600 \mathrm{fps}$ and a microscope with a maximum 320-fold magnification. 


\section{Experimental results}

As an example of boiling behavior in the low heat flux region at high pressures, Fig. 4 shows the results obtained at 5MPa. In Fig.4-(a), fine primary bubbles detach from two active nucleation sites. The number of active nucleation sites increases with increases in the heat flux (Fig.4-(b)). Consequently, the primary bubbles coalesce partly and some of the bubbles detach as coalesced bubbles (Fig.4-(c)). The heat flux of Fig.4-(c) is only about 1\% of the CHF, and it is one of the features of boiling under high pressures that the coalescence of primary bubbles commences in this low heat flux region. The detachment diameter of the primary bubbles differs from one nucleation site to another, and the primary bubbles with higher detachment frequency are smaller in size. The detachment frequencies of primary bubbles lied in the range about 50 to $150(1 / \mathrm{s})$. Figure 5 shows the present results of the primary bubble diameters at detachment together with Semeria's data [15] for primary bubbles. The predicted values by the Fritz equation with a contact angle of 50 degrees, and by the following empirical equation for water by Cole and Rohsenow [19] are also shown in Fig.5.

$$
N_{E O}=1.5 \times 10^{-4}\left(N_{J a} *\right)^{5 / 4} .
$$

In equation (2), $N_{E o}$ and $N_{J a} *$ are the Eötvös and modified Jakob numbers defined respectively as

$$
\begin{aligned}
& N_{E o}=g\left(\rho_{l}-\rho_{v}\right) D_{b}{ }^{2} / \sigma, \\
& N_{J a}{ }^{*}=\rho_{l} C_{p l} T_{\text {sat }} /\left(\rho_{v} H_{f g}\right) .
\end{aligned}
$$

The present data scatter widely in the high pressure region, and those at $5 \mathrm{MPa}$ are larger than Semeria's data obtained with the $2 \mathrm{~mm}$ in diameter horizontal cylinder, but show a similar tendency to that of Semeria's results where the primary bubbles diminish in size almost inversely in proportion to pressure.

Figure 6 shows the changes in the boiling behaviors with increases in the 
heat flux at 1, 3, and 5MPa. The diameters of detached coalesced bubbles markedly increase with increasing heat flux. Especially near the CHF point, the coalesced bubbles detach from the heating surface as a large deformed spheroidal bubble with a main axis of 10 to $15 \mathrm{~mm}$ even at the high 5MPa pressure.

Figure 7 shows the changes in the equivalent diameters of detached coalesced bubbles with heat flux at the various pressures. When the shape of the bubble deviates from spherical, the bubble was approximated as a spheroid and the diameter was calculated as that of a sphere with volume equivalent to the spheroid. The up-pointing arrows in the figure indicate the direction of the heat flux increase. At each pressure, the coalesced bubbles further coalesce in the low heat flux region, and the diameter of detached bubbles increases continuously with increases in the heat flux. Especially, at the CHF point (indicated by arrows in the figure), the bubbles detach as huge coalesced bubbles with diameters several tens to hundreds of times larger than those of the primary bubbles.

In Fig.7, the values of the Taylor instability wavelength given by the following equation are also shown.

$$
\lambda=2 \pi \sqrt{\sigma / g\left(\rho_{l}-\rho_{v}\right)} .
$$

The Taylor instability wavelength lies close to the maximum diameter of the coalesced bubbles at each pressure. This result may suggest that the maximum diameter of the detached coalesced bubbles is restrained by the Taylor instability. At heat fluxes lower than the CHF, however, the detached bubble diameter is smaller than the Taylor instability wavelength, and the behaviors of such smaller bubbles would be independent of the Taylor instability.

Figure 8 arranges the detached bubble diameters with the vapor blowing rate $G_{0}\left(=q / \rho_{V} H_{f g}\right)$. It shows that the diameters of the detached bubbles arrange fairly well against the vapor blowing rate $G_{0}$. Here, the points indicated by arrows 
in the figure correspond to the CHF at different pressures.

Figure 9 shows the results of the detachment frequency of the coalesced bubbles at each pressure. In the figure, the ranges of the heat flux corresponding to the respective data are also shown. The detachment frequencies were determined by counting the number of bubbles passing through a fixed location from the heating surface during a given period of time. Bobrovich et al. [16] measured the detachment frequency in the $0.1 \mathrm{MPa}$ to $5.35 \mathrm{MPa}$ range of pressures for water boiling on a $2 \mathrm{~mm}$ wide rectangular heating surface, and obtained the results that the detachment frequencies are insensitive to the heat flux. The detachment frequencies of the present experiment were also almost the constant value within the scatter of the data independent of the heat flux. The dependence on pressure is also weak and the average values of the data increase slightly with pressure.

Figure 10 shows the measured results of $\mathrm{CHF}$, with the predicted values by Zuber [20] with $K=0.131$ in equation (6) and by Lienhard and Dhir [18] with $K=0.149$.

$$
q_{C H F}=K \rho_{v}^{1 / 2} H_{f g}\left\{g\left(\rho_{l}-\rho_{v}\right) \sigma\right\}^{1 / 4} .
$$

It has been known that the CHF values predicted by the Zuber and Lienhard correlations agree well with the ethanol data of the CHF by Cichelli and Bonilla [21] measured for an upward facing horizontal surface in a wide range of pressures. For water data of the CHF, the correlations predict smaller values than the data, but agree with the variations with pressure.

As for the CHF of water at high pressures, Kazakova [22,23] carried out measurements with horizontal wires of $0.135 \mathrm{~mm}, 0.15 \mathrm{~mm}$, and $0.29 \mathrm{~mm}$ diameters at pressures up to 20MPa. In Fig.10, however, there is no comparison with the data by Kazakova because the Zuber and Lienhard correlations were 
derived for horizontal flat surfaces.

\section{Prediction of the CHF by the macrolayer dryout model}

As shown in the previous section, large coalesced bubbles which are large enough to have the liquid macrolayer on the bottom are formed near the $\mathrm{CHF}$ even at the $5 \mathrm{MPa}$ pressure. This suggests that the macrolayer dryout model is applicable to the $\mathrm{CHF}$ at high pressures.

This section derives an empirical correlation for the detachment frequency of the coalesced bubbles, and the $\mathrm{CHF}$ is predicted with this empirical correlation and correlations for macrolayer thicknesses previously proposed for near atmospheric pressures.

As suggested in Figs.6 and 7, the bubbles may grow by vapor supply from the heating surface due to vaporization of the liquid layer (macrolayer and/or microlayer) and by absorbing smaller surrounding bubbles, leading to large coalesced bubbles. Therefore, the growth process of the coalesced bubbles is complicated and accurate modeling would be difficult. Here, it is assumed that the coalesced bubbles are spherical, and grow by a uniform vapor supply from an area of $\Pi R_{d}^{2}$ (where $R_{d}$ is the radius of coalesced bubbles at detachment) on the heating surface. Then the bubble growth is given by

$$
\frac{d}{d t}\left(\frac{4}{3} \pi r^{3}\right)=\pi R_{d}^{2} G_{0}
$$

Solving equation (7) with the initial condition $r=0$ at $t=0$, the relation between diameter and frequency of detached bubbles becomes

$$
D_{d}=3 G_{0} / 2 f \text {. }
$$

There are various forces acting on the coalesced bubbles, such as buoyancy, drag, added mass inertia, momentum flux by vapor blowing, and a wake flow effect of 
the previously detached coalesced bubbles. The purpose of this section is to derive a correlation arranging the measured data, and it was assumed that the coalesced bubbles move under a force balance between buoyancy and drag forces. The momentum equation of a coalesced bubble is, therefore, written as

$$
\frac{4}{3} \pi r^{3}\left(\rho_{l}-\rho_{v}\right) g=\frac{\rho_{l}}{2} C_{D} \pi r^{2}\left(\frac{d s}{d t}\right)^{2}
$$

The drag coefficient in the right hand side of equation (9) is assumed as similar to a bubble rising in a stagnant liquid as

$$
C_{D}=C_{0}\left(R e \cdot M^{0.25}\right)^{m}
$$

In equation (10), the bubble Reynolds number is defined by

$$
R e=\frac{2 r}{v_{l}} \cdot \frac{d s}{d t}
$$

and the exponent $m$ in equation (10) is determined from the experimental data. Solving equations (7) to (10) and assuming that the coalesced bubble detaches at $s_{S}=R_{d}$, then the detachment frequency is given by the following equation.

$$
f=A \cdot\left\{\frac{g\left(\rho_{l}-\rho_{\nu}\right)}{\rho_{l}}\right\}^{\frac{1}{1-m}}\left(\frac{v_{l}}{M^{0.25}}\right)^{\frac{m}{1-m}} G_{0} \frac{2 m+1}{m-1},
$$

where $A$ is a group of constants and given by

$$
A=2^{\frac{3 m+5}{1-m}} 3^{\frac{m}{m-1}}\left(\frac{m+2}{2 m+7}\right)^{\frac{m+2}{1-m}} C_{0}^{\frac{1}{m-1}}
$$

With the exponent $m$ in equation (12) $-1 / 2$ from the experimental results where the detachment frequency $f$ is independent of the vapor blowing rate $G_{0}$, and determining the constant $C_{O}$ in equation (13) from the measured data leads to the final form of equation (12) as

$$
f=0.6\left\{\frac{\left(\rho_{l}-\rho_{v}\right) g}{\rho_{l}}\right\}^{2 / 3}\left(\frac{v_{l}}{M^{0.25}}\right)^{-1 / 3} .
$$


The result predicted by equation (14) is shown in Fig.9. The variations in the predicted results with pressure agree well with the experimental results. The relations between the diameter of the detached bubbles and the vapor blowing rate at pressures of 1 and $5 \mathrm{MPa}$, which are obtained by substituting equation (14) into equation (8), are shown as solid and dashed lines in Fig.8. Because the dependence of the detachment frequency on pressure is weak, the predicted results of the diameter at detachment for different pressures are expressed approximately as a single curve. The predicted curves agree well with the data near the CHF at each pressure. The better agreement between predicted and measured values in the higher $G_{0}$ region is probably because that the assumption of uniform vapor supply becomes more accurate as $G_{0}$ increases.

There are no data of the macrolayer thickness measured at high pressures and the previously reported correlations of the macrolayer thickness have been evaluated based on the data around atmospheric pressure. Haramura and Katto [24] assumed a situation where thin vapor stems penetrate the macrolayer and proposed a correlation for the the macrolayer thickness as

$$
\delta=0.00536 \frac{\sigma}{\rho_{v}}\left(\frac{\rho_{v}}{\rho_{l}}\right)^{0.4}\left(1+\frac{\rho_{v}}{\rho_{l}}\right) \cdot G_{0}{ }^{-2} .
$$

This correlation agrees fairly well with the data of Shoji [5] in the lower heat flux region. Rajvanshi et al. [4] measured the macrolayer thicknesses for various liquids at atmospheric pressure using a conductance probe, and found that the data agree with twice the magnitude of the Haramura and Katto correlation as

$$
\delta=0.0107 \frac{\sigma}{\rho_{v}}\left(\frac{\rho_{v}}{\rho_{l}}\right)^{0.4}\left(1+\frac{\rho_{v}}{\rho_{l}}\right) \cdot G_{0}{ }^{-2} .
$$

Kumada and Sakashita [25] proposed a following semi-empirical equation based on an assumption that the macrolayer is formed by a lateral further coalescence of 
already coalesced bubbles, which are formed by coalescence of smaller primary bubbles.

$$
\delta_{l}=0.786\left\{\frac{v_{l}^{8} \sigma^{11}}{\rho_{l}^{6} g^{5}\left(\rho_{l}-\rho_{v}\right)^{5}}\right\}^{1 / 24} G_{0}^{-5 / 6} .
$$

Equation (17) correlates the data of the macrolayer thickness well. The data here were indirectly determined using equation (1), from the data of the $\mathrm{CHF}$ and frequency of coalesced bubbles for various liquids in the pressure range from $0.03 \mathrm{MPa}$ to $0.4 \mathrm{MPa}$.

Assuming that equations (15) to (17) also apply at high pressures, the CHF was predicted by substituting equations (14) and each of equations (15) to (17) into equation (1). The predicted results are shown in Fig.10. The predicted values with equation (16) by Rajvanshi et al. and equation (17) by Kumada and Sakashita agree with the measured $\mathrm{CHF}$ within the scatter of the data. The predicted values with equation (15) by Haramura and Katto are smaller than the data as equation (16) predicts half the macrolayer thickness of equation (17).

The increases in the predicted $\mathrm{CHF}$ with pressure are mainly attributed to the macrolayers calculated from equations (15), (16), and (17) becoming thicker because an increase in pressure lowers the vapor blowing rate $G_{0}$ at the $\mathrm{CHF}$ point, as shown in Fig.8.

\section{Conclusions}

Observations of boiling behaviors from low heat flux to the CHF were carried out for saturated water boiling on a horizontal, upward-facing rectangular $4 \mathrm{~mm}$ wide plate in the pressure range from atmospheric to $5 \mathrm{MPa}$. Further, the CHF was measured from atmospheric to $7 \mathrm{MPa}$, and compared to the predicted values derived with the macrolayer dryout model. The conclusions obtained in the 
present paper may be summarized as follows:

(1) The diameter of detached primary bubbles decreases in almost inverse proportion to the pressure, similar to the results with a $2 \mathrm{~mm}$ diameter horizontal cylinder measured by Semeria. The primary bubbles formed at high pressures begin to coalesce at very low heat fluxes: $q / q_{C H F}$ of about 0.01 at $5 \mathrm{MPa}$.

(2) The equivalent diameter of the detached coalesced bubbles increases continuously with increases in the heat flux and reaches 8 to $10 \mathrm{~mm}$ near the CHF, and it is of sufficient size to form a liquid macrolayer at the bottom of the coalesced bubble.

(4) The detachment frequencies of coalesced bubbles are insensitive to the changes in heat flux and pressure. Therefore, the tendency for CHF to increase with increases in pressure is not due to the increase in the detachment frequency of the coalesced bubbles.

(5) The CHF predicted using the empirical correlation of detachment frequency and the available correlations of macrolayer thickness derived near atmospheric pressures agrees fairly well with the data of the CHF measured from 0.1 to $7 \mathrm{MPa}$. This would suggest that the macrolayer dryout model is an appropriate model for the $\mathrm{CHF}$ on flat surfaces at high pressures. However, there is no information about the liquid-vapor behaviors close to the heating surface at high pressures. Further research is needed to clarify the CHF mechanism at high pressures. 


\section{REFERENCES}

[1] Katto, Y. and Yokoya, S., Principal mechanism of boiling crisis in pool boiling, International Journal of Heat and Mass Transfer, 11,993-1002(1968).

[2] Iida, Y. and Kobayasi, K., An experimental investigation on the mechanism of pool boiling phenomena by a probe method, Proceedings of the 4th International Heat Transfer Conference, Paris, 5(1970), 1-11.

[3] Bhat, A.M., Prakash, R. and Saini, J.S., Role of macrolayer evaporation in pool boiling at high heat flux, International Journal of Heat and Mass Transfer, 29, 1953-1961(1986).

[4] Rajvanshi, A.K., Saini, J.S. and Prakash,R., Investigation of macrolayer thickness in nucleate pool boiling, International Journal of Heat and Mass Transfer, 35, 343-350(1992).

[5] Shoji, M., A study of steady transition boiling of water: experimental verification of macrolayer evaporation model, Pool and External Flow Boiling, Dhir, V.K. et al. ed., ASME, (1992), 237-242.

[6]Auracher, H. and Marquardt, W., Heat transfer characteristics and mechanisms along entire boiling curves under steady-state and transient conditions, International Journal of Heat and Fluid Flow 25(2) (2004) 223-242.

[7] Kirby, D.B. and Westwater, J.W., Bubble and vapor behavior on a heated plate during pool boiling near burnout, Chemical Engineering Progress Symposium Series, 61, 238-248(1965).

[8] Torikai, K. and Yamazaki, T., The contact area of boiling bubbles on the heating surface, Transactions of JSME, 31-223, 440-445(1965)(in Japanese). [9] Ono, A. and Sakashita, H., Liquid-vapor structure near heating surface at high heat flux in subcooled pool boiling, International Journal of Heat and Mass Transfer, Vol.50 (2007), pp.3481-3489. 
[10] Ono, A. and Sakashita, H., Measurement of surface dryout near heating surface at high heat fluxes in subcooled pool boiling, International Journal of Heat and Mass Transfer, 52, 814-821(2009).

[11] Iida, Y. and Kobayasi, K., On the behavior of generating vapor bubbles in saturated pool boiling: (Part 2,the behavior near the burn-out point and in transition boiling), Transactions of JSME, 36 -283,446-453(1970), (in Japanese).

[12] Lee, L.Y.W., Chen, J.C. and Nelson, R.A., Liquid-solid contact measurements using a surface thermocouple temperature probe in atmospheric pool boiling water, International Journal of Heat and Mass Transfer, 25, 1415-1423(1985). [13] Shoji, M., Witte, L.C., Yokoya, S. and Ohshima, M., Liquid-solid contact and effects of surface roughness and wettability in film and transition boiling on a horizontal large surface, Proceedings of 9th International Heat Transfer Conference, Jerusalem, 2, 135-141(1990).

[14] Sakashita, H. and Kumada, T., Trends in Heat Mass \& Momentum Transfer, 6, edited by Hahne, E., et al., Research Trends, 1-36(2000).

[15] Semeria, R., High-speed cinematography and pool boiling under high pressure, La Houlle Blanche, 6, 679-687(1963) (in French).

[16] Bobrovich, G.I. and Mamontva, N.N., A study of the mechanism of nucleate boiling at high heat flux, International Journal of Heat and Mass Transfer, 8, 1421-1424(1965).

[17] Nishikawa,K., Fujita,Y., Nawata,Y. and Hirahaya, K., Effect of pressure on nucleate boiling heat transfer of water, Memoirs of the faculty of Eng. Kyushu Univ., 30-2(1970).

[18] Lienhard,J.H. and Dhir, V.K., Hydrodynamic prediction of peak pool-boiling heat fluxes from finite bodies, Journal of Heat Transfer, Transactions of ASME, Series C, 95-2, 152-158(1973). 
[19] Cole, R. and Rohsenow, W.M., Correlation of bubble departure diameter for boiling of saturated liquids, Chemical Engineering Progress Symposium Series, 65-92, 211-213(1969).

[20] Zuber, N., Hydrodynamic aspects of boiling heat transfer, AEC report, No.AECU-4439, (1959).

[21] Cichelli, M.T. and Bonilla, C.F., Heat transfer to liquids boiling under pressure, Transactions of AIChE, 41, 755-787(1945).

[22]Kazakova, E.A., Influence of pressure on maximum heat transfer to boiling water in large volume, Izvestia An SSSR, OTN No.1 (1949) (in Russian).

[23]Kazakova, E.A., Maximum heat transfer to boiling water at high pressures, The Engineers' Digest, 12-3, 81-85(1951).

[24] Haramura,Y. and Katto,Y., A new hydrodynamic model of critical heat flux, applicable widely to both pool and forced convection boiling on submerged bodies in saturated liquids, International Journal of Heat and Mass Transfer, 26, 389-399(1983).

[25] Kumada, T. and Sakashita. H., Pool boiling heat transfer- II.Thickness of liquid macrolayer formed beneath vapor masses, International Journal of Heat and Mass Transfer, 38, 979-987(1995). 
Captions of figures

Figure $1 \quad$ Coalesced bubble diameter at high pressures measured by Semeria and Bobrovich et al.

Figure 2 High pressure vessel used in the experiments.

Figure 3 Test section and its assembly in the high pressure vessel.

Figure $4 \quad$ Boiling behavior at low heat fluxes $(p=5.0 \mathrm{MPa})$.

Figure $5 \quad$ Primary bubble diameters at detachment.

Figure 6 Boiling behaviors at different heat fluxes. (a) $p=1 \mathrm{MPa}$, (b) $p=3 \mathrm{MPa}$, and (c) $p=5 \mathrm{MPa}$.

Figure $7 \quad$ Changes in detached bubble diameter with heat flux at various pressures.

Figure 8 Changes in diameters of detached coalesced bubbles with vapor blowing rate.

Figure 9 Changes in detachment frequencies of coalesced bubbles with pressure.

Figure 10 Measured data of $\mathrm{CHF}$ and calculated results with the Zuber and Lienhard correlations and with the macrolayer dryout model (details are discussed in Section 4). 


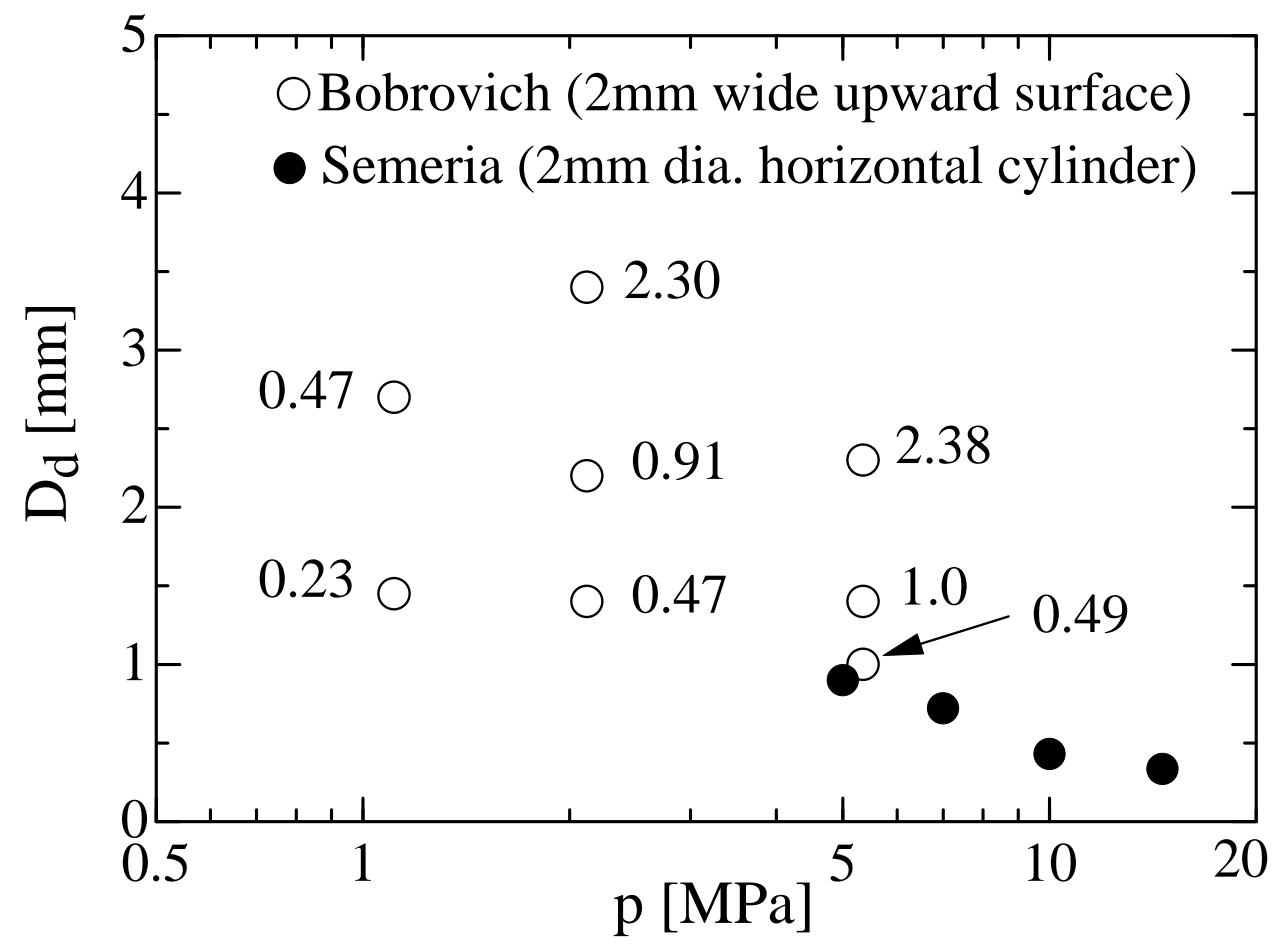

Figure 1 Coalesced bubble diameters at high pressure measured by Semeria and Bobrovich et al. 


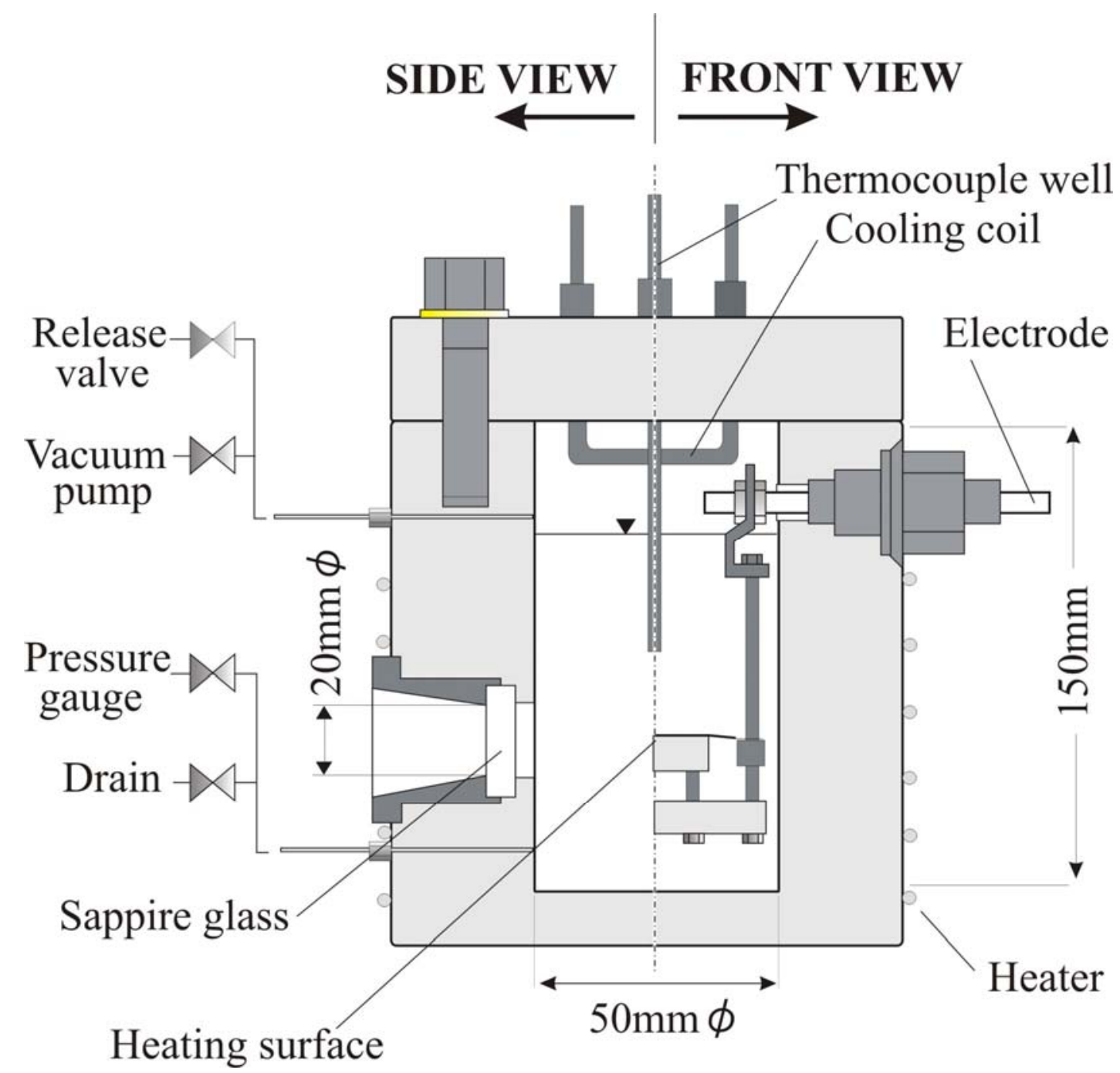

Figure 2 High pressure vessel used in the experiments. 


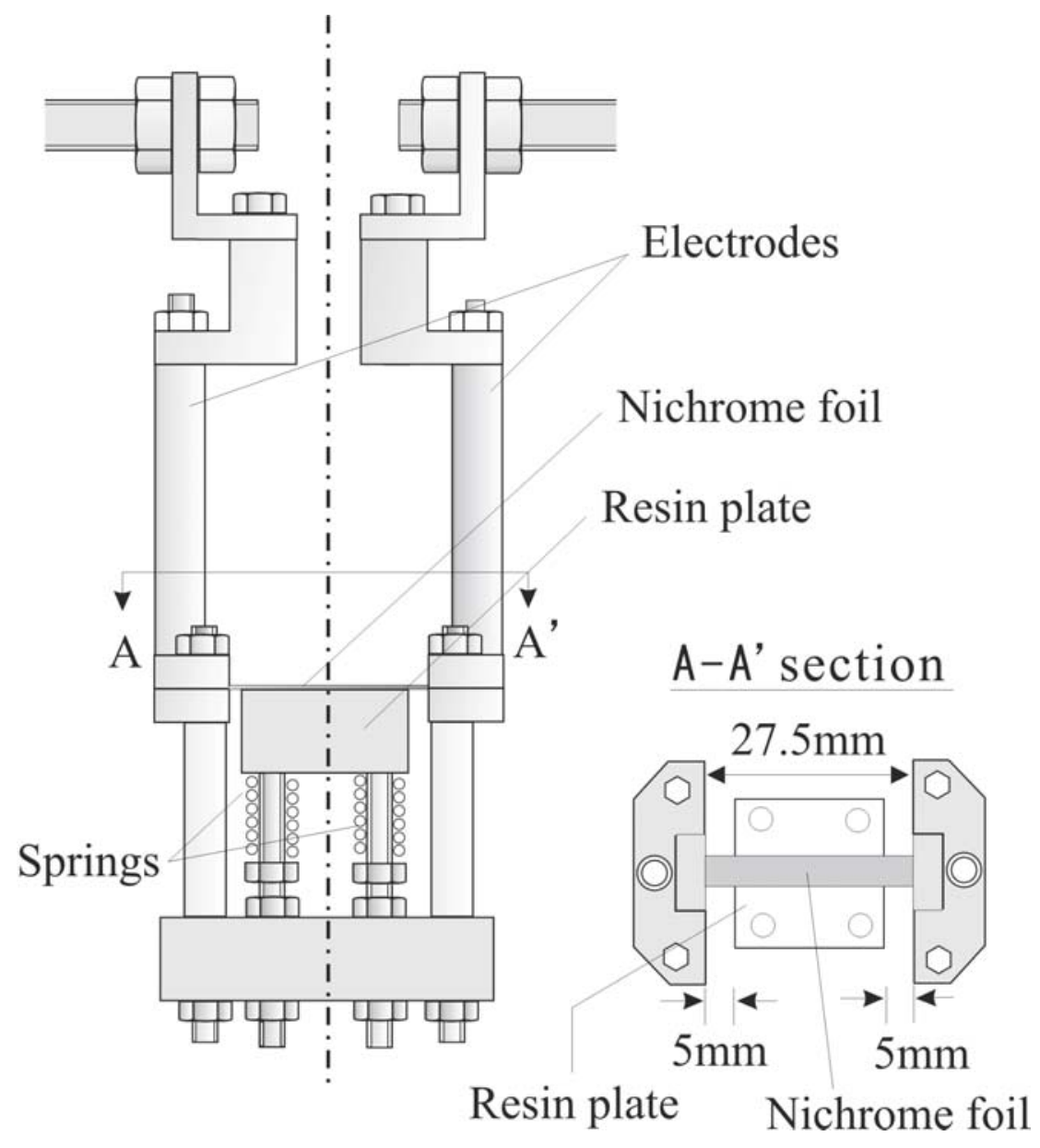

Figure 3 Test section and its assembly in the high pressure vessel. 


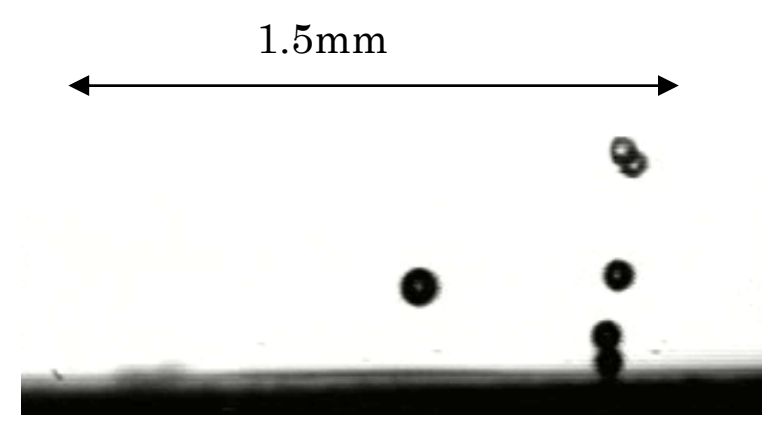

(a) $\mathrm{q}=0.0212 \mathrm{MW} / \mathrm{m}^{2}$

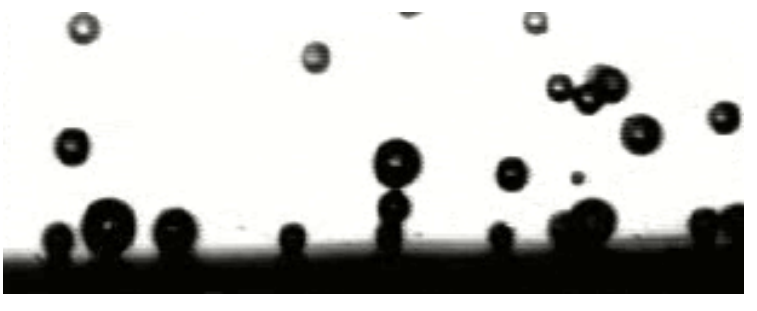

(b) $\mathrm{q}=0.0377 \mathrm{MW} / \mathrm{m}^{2}$

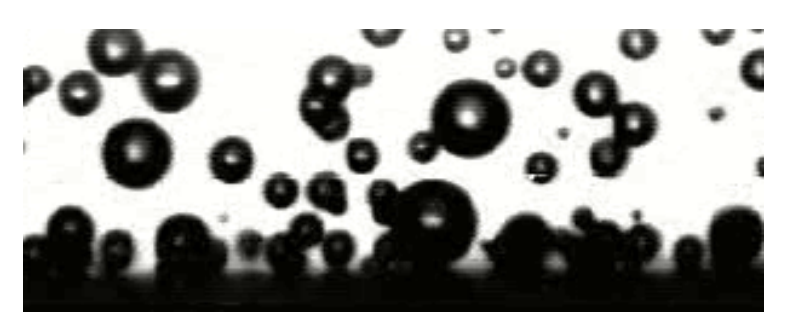

(c) $\mathrm{q}=0.0614 \mathrm{MW} / \mathrm{m}^{2}$

Figure 4 Boiling behavior at low heat fluxes $(p=5.0 \mathrm{MPa})$. 


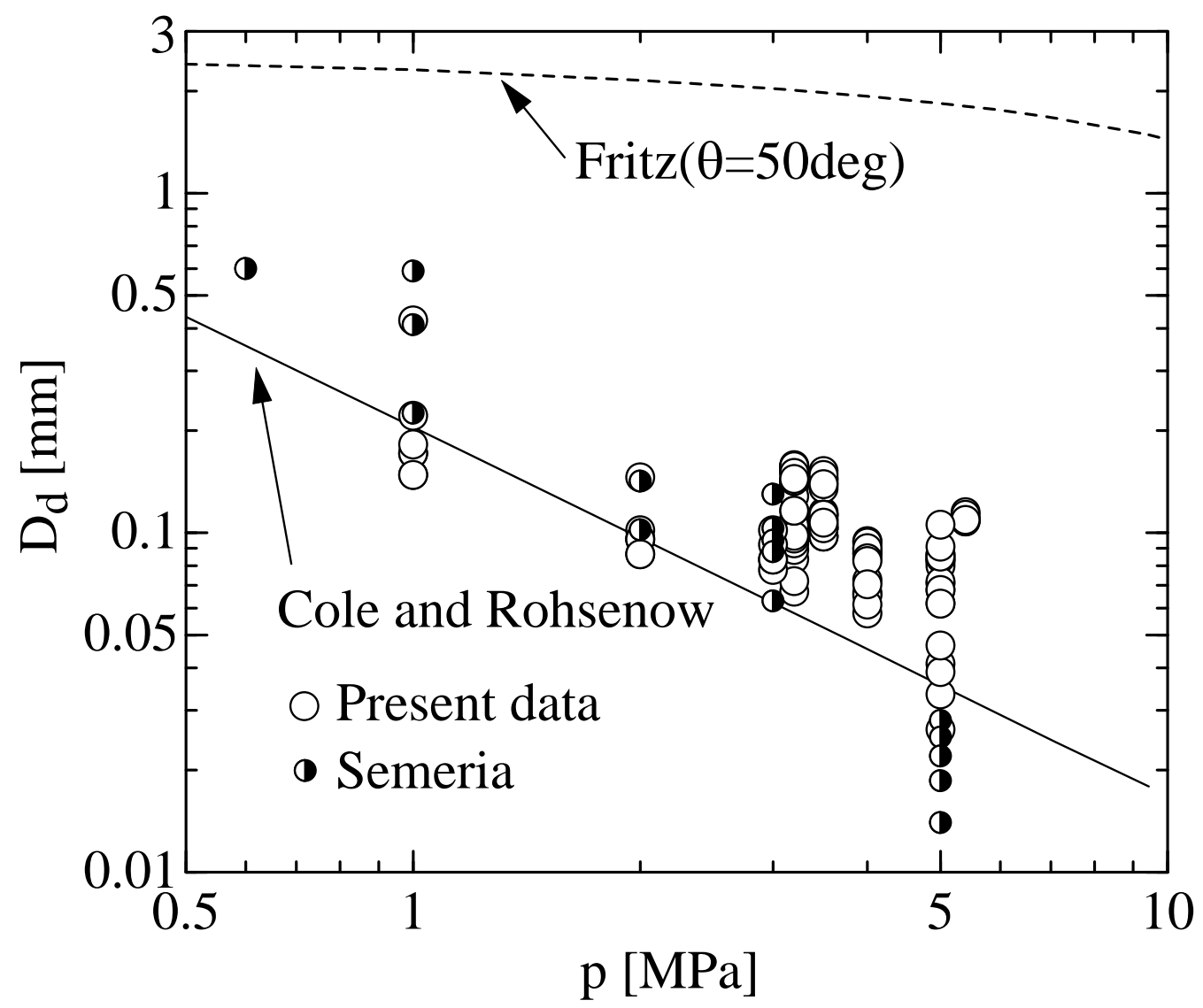

Figure 5 Primary bubble diameters at detachment. 

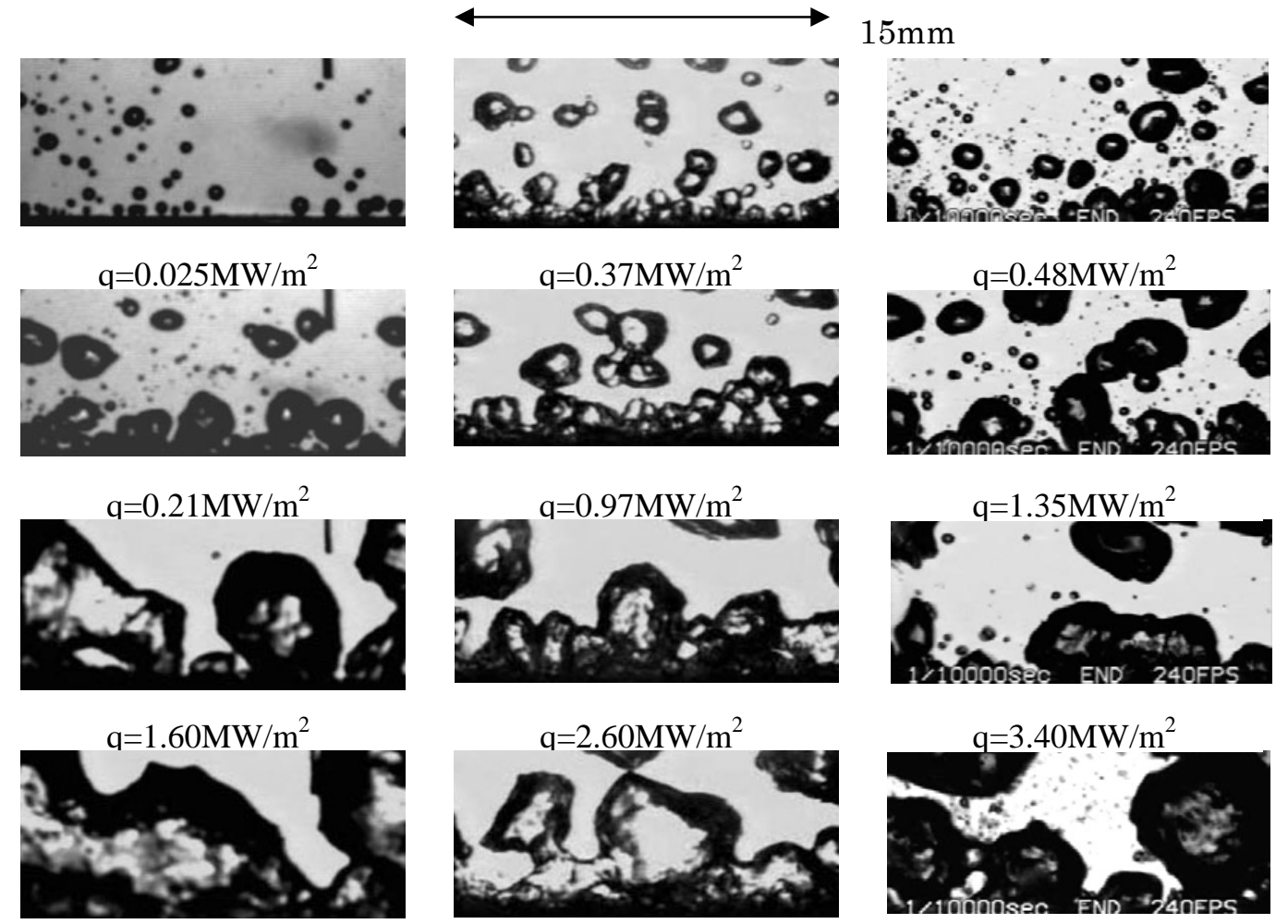

$\mathrm{q}=4.94 \mathrm{MW} / \mathrm{m}^{2}$

$\mathrm{q}=5.05 \mathrm{MW} / \mathrm{m}^{2}$

(a) $1 \mathrm{MPa}$

(b) $3 \mathrm{MPa}$

$\mathrm{q}=7.20 \mathrm{MW} / \mathrm{m}^{2}$

(c) $5 \mathrm{MPa}$

Figure 6 Boiling behaviors at different heat fluxes. (a) $p=1 \mathrm{MPa}$, (b) $p=3 \mathrm{MPa}$, and (c) $p=5 \mathrm{MPa}$. 


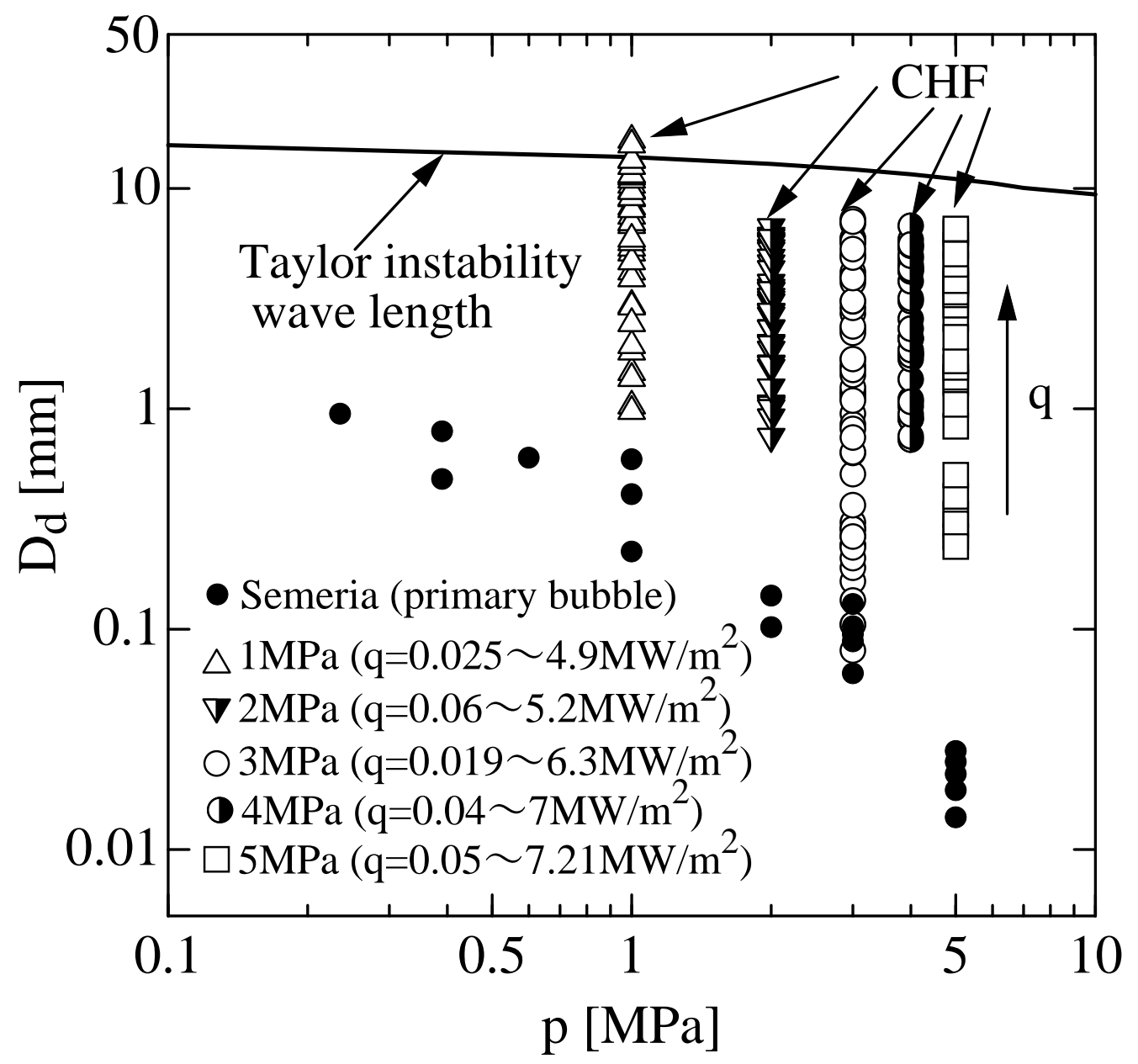

Figure 7 Changes in detached bubble diameter with heat flux at various pressures. 


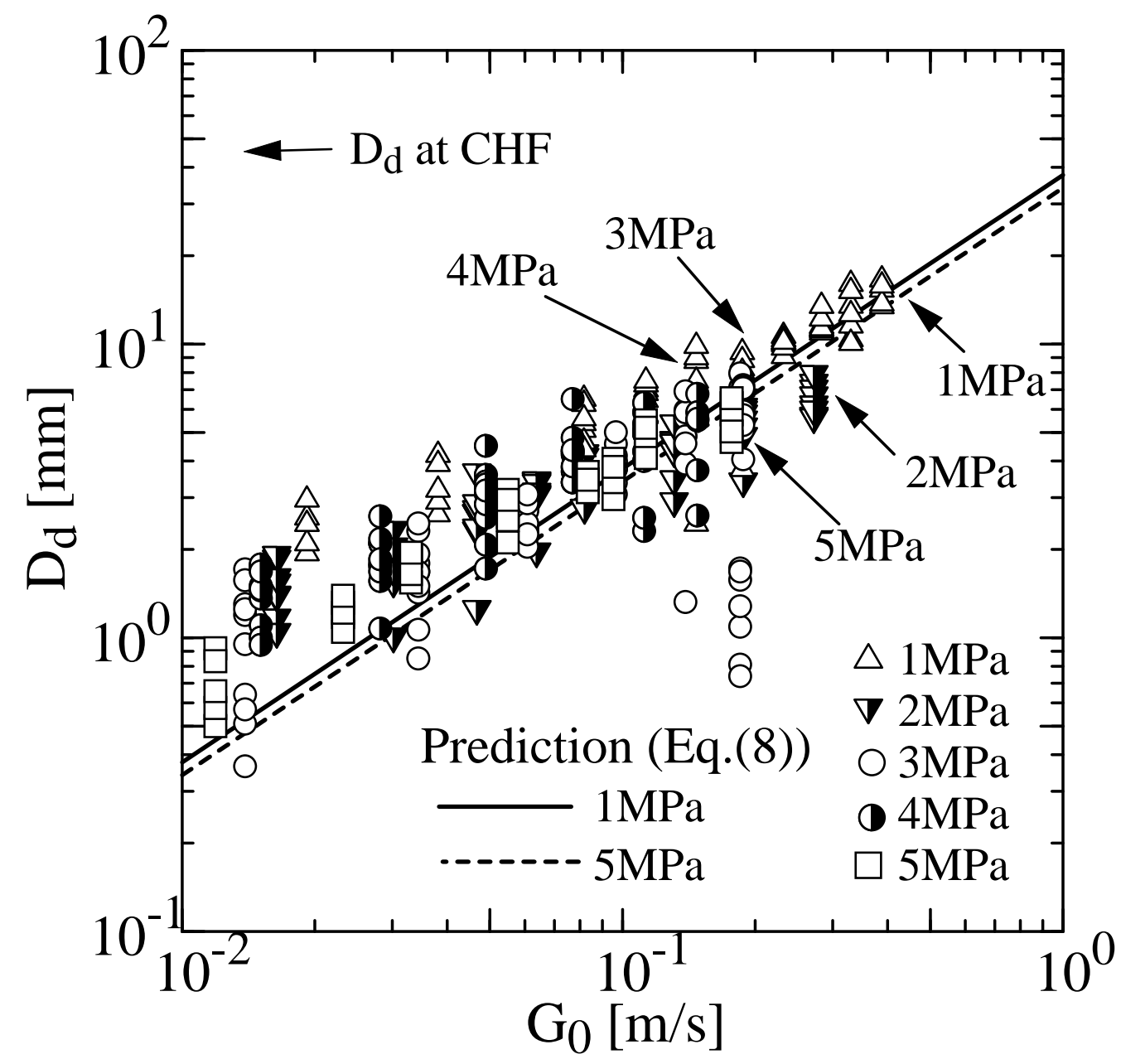

Figure 8 Changes in diameters of detached coalesced bubbles with vapor blowing rate. 


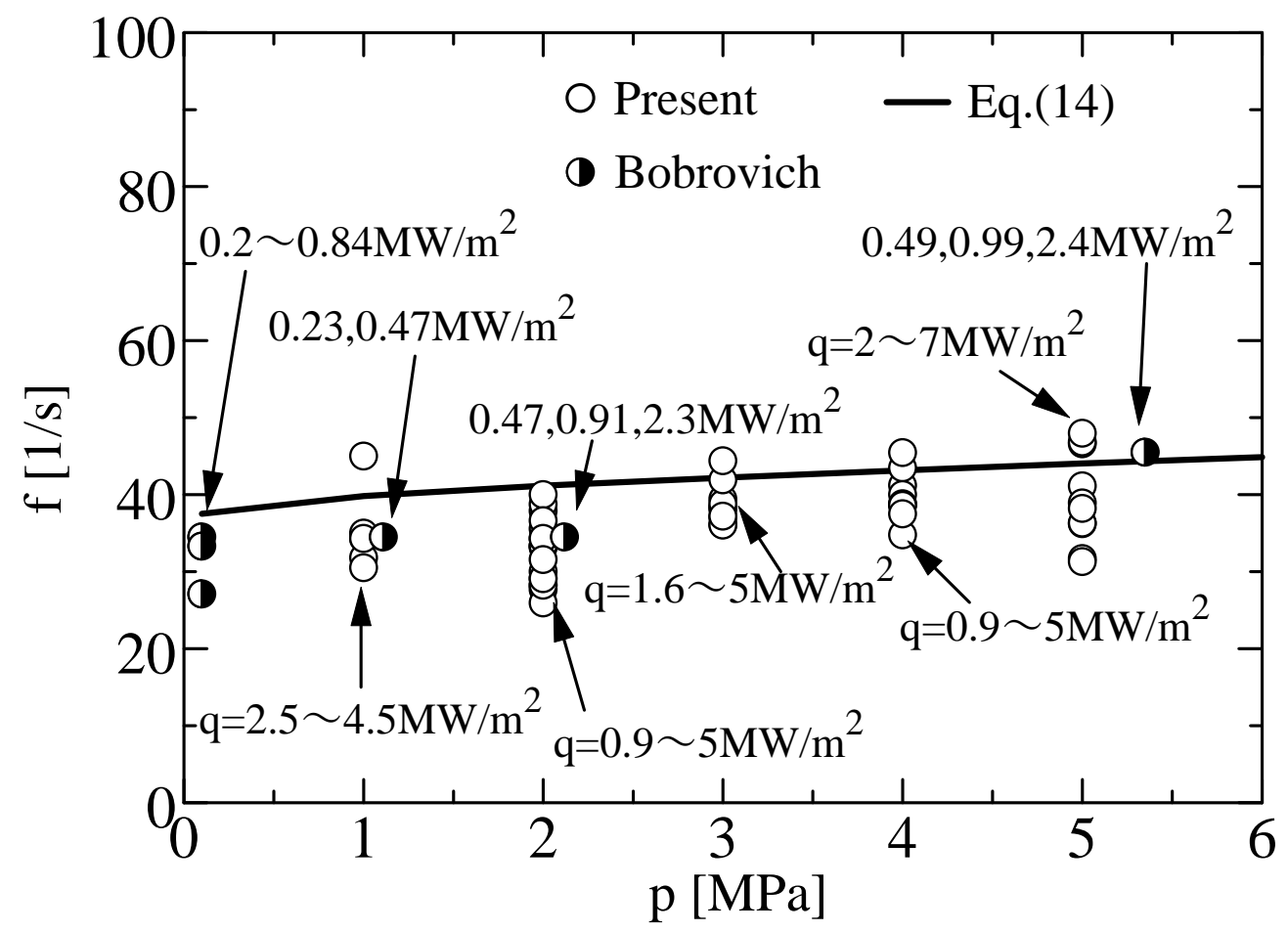

Figure 9 Changes in detachment frequencies of coalesced bubbles with pressure. 


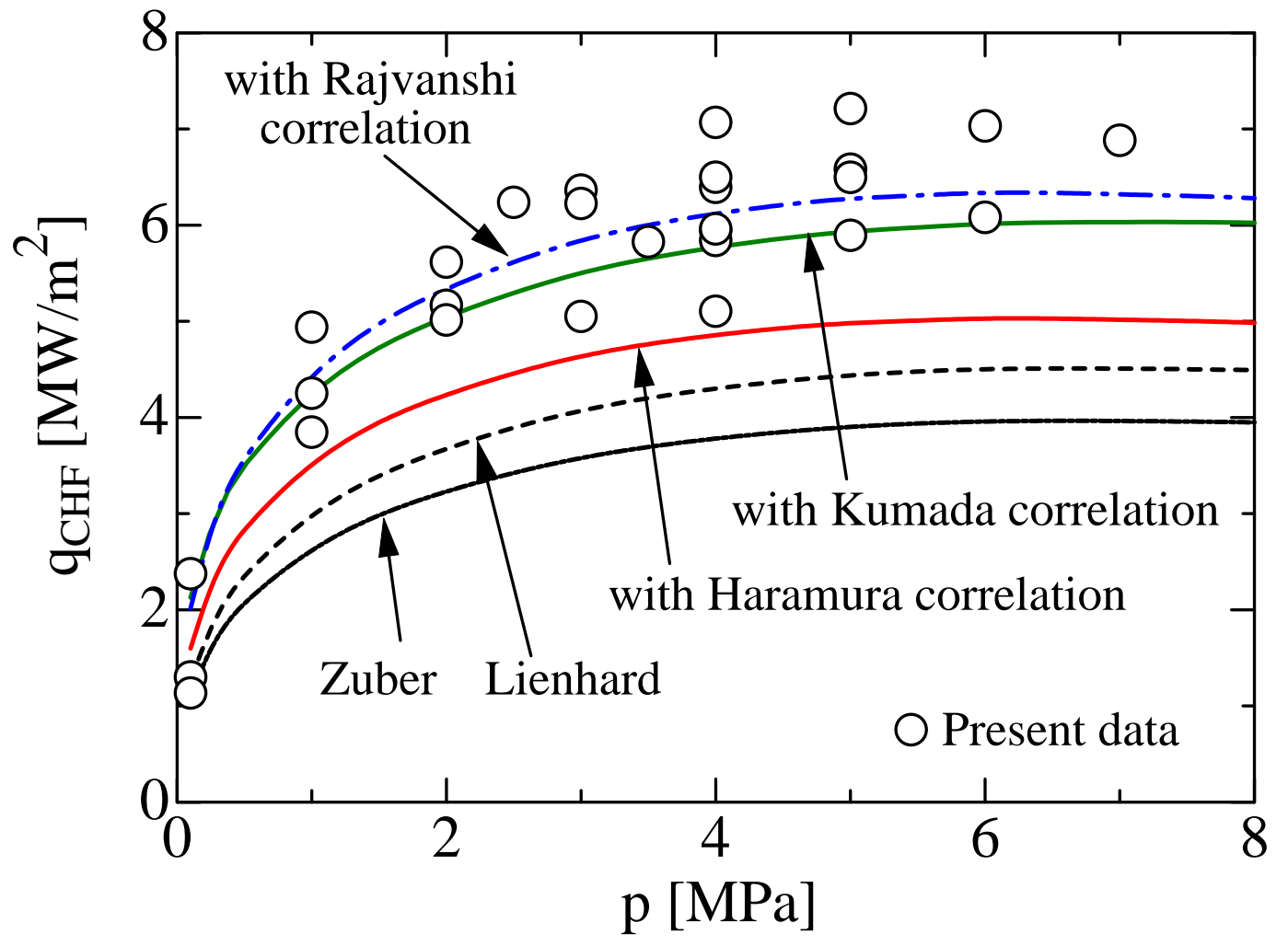

Figure 10 Measured data of $\mathrm{CHF}$ and calculated results with the Zuber and Lienhard correlations and with the macrolayer dryout model (details are discussed in Section 4). 